\title{
Three-dimensional fatigue crack propagation analysis of welded steel beam based on global-local numerical model
}

\author{
Liang Zong ${ }^{1}$ and Gang Shi ${ }^{2 *}$
}

\author{
*Correspondence: shigang@ \\ tsinghua.edu.cn \\ ${ }^{2}$ Key Laboratory of Civil Engineering \\ Safety and Durability of China \\ Education Ministry, Department of \\ Civil Engineering, Tsinghua \\ University, Beijing 100084, China \\ Full list of author information is \\ available at the end of the article
}

\begin{abstract}
The existing fatigue assessment approaches were mainly conducted on the component level. The interaction of local component damage and the global response cannot be well addressed. In this study, three-dimensional (3D) fatigue crack propagation analysis approach based on global-local numerical model was implemented, and examined to be accurate and effective through a series of systematic experimental data obtained by Fisher. Afterwards, the approach was introduced into a typical steel truss bridge for realizing more refined fatigue assessment from the global structural level. The fatigue performance of the longitudinal steel welded beam in the steel truss bridge was investigated based on global-local model and local model respectively. It was found that there is no difference in terms of the fatigue crack growth mechanism between the simulation between global-local model and local model due to that the stress level of the whole structure is relatively low. At last, the effect of heavy haul train operation on the fatigue performance of the steel truss bridge was analyzed. It was observed that the residual life of the longitudinal steel welded beam would have an obvious reduction when the axle load was increasing. The research work in this study presents a technical solution for the fatigue assessment of the global structure and can provide beneficial reference for relevant practical engineering projects.
\end{abstract}

Keywords: 3D fatigue crack propagation, Fatigue assessment, Welded steel beam, Global-local model, Heavy haul train, Fracture mechanics

\section{Introduction}

The fatigue strength of welded steel beam is the significant design criterion for many steel bridges. Extensive studies (e.g. Wilson 1948; Comeau and Kulak 1979) have been conducted to investigate the fatigue performance of welded steel beams, among which, Fisher et al. $(1970,1974)$ had carried out a comprehensive experimental examination on steel beam in the early 1970s. The relevant research results have led to the formation of the design $S-N$ curve in many design codes such as AASHTO (1995) and Eurocode (BSI 2005a), which makes the fatigue design of welded steel beams much easier to operate. However, two issues will be triggered when dealing with an existing steel bridge. The first one is that it is difficult to estimate the residual fatigue life of the existing bridge, especially when the loading history

(c) The Author(s). 2021 Open Access This article is licensed under a Creative Commons Attribution 4.0 International License, which permits use, sharing, adaptation, distribution and reproduction in any medium or format, as long as you give appropriate credit to the original author(s) and the source, provide a link to the Creative Commons licence, and indicate if changes were made. The images or other third party material in this article are included in the article's Creative Commons licence, unless indicated otherwise in a credit line to the material. If material is not included in the article's Creative Commons licence and your intended use is not permitted by statutory regulation or exceeds the permitted use, you will need to obtain permission directly from the copyright holder. To view a copy of this licence, visit http://creativecommons.org/licenses/by/4.0/. 
of the bridge is unclear. This is a common disadvantage for the kind of $S-N$ based fatigue assessment approaches. The second one is that the interaction of local component damage and the global response cannot be considered as almost all the investigations so far can only focus on the component level with unchanged boundary conditions. Nevertheless, the globallocal interaction should be well addressed for an integrated structure system.

As early as in 1970, Fisher et al. (1970) pointed that Fracture Mechanics is a promising tool for improving fatigue evaluation. During the past five decades, a huge amount of research (e.g Ibsø and Agerskov 1996; Barsoum 2008; Hobbacher 2009) have been implemented to enhance the application of Fracture Mechanics based fatigue assessment approach. It has been proved that Fracture Mechanics based approach combining suitable site inspection data will work properly for structures which has already been under service. It is worth mentioning that the loading history of the structure is unnecessary and therefore the first issue above mentioned can be addressed. For the second issue, it is a natural thought to consider the interaction of local damage and global response through global-local numerical modelling (Zhou et al. 2016), which could produce satisfied accuracy and computation efficiency. Upon all the inspiring achievements in the relevant field, the motivation of this work is activated. In the following study, three-dimensional (3D) fatigue crack propagation analysis approach based on globallocal numerical model will be examined carefully. Then this approach will be employed to estimate the residual life of welded steel beams in a practical steel truss railway bridge on the basis of the global-local modelling.

\section{Verification of 3D fatigue crack propagation analysis based on global-local numerical model}

From the view of Fracture Mechanics, the total fatigue life of steel structural details generally consists of two parts, fatigue crack initiation life and fatigue crack propagation life. For large scale engineering structures, especially for weldments, the micro-defects are inevitable. Therefore, it is a common practice to take the fatigue crack propagation life as the total fatigue life to produce a conservative prediction (Zong et al. 2017a, b, c). The fatigue crack propagation analysis approach has been through an enormous development until now, from only working properly on Mode I crack with prescribed linear locus, to working perfectly on 3D mixed mode crack along actual growth route. Nevertheless, all these analyses were usually implemented based on refined finite element (FE) model with solid elements, instead of global-local model with mixed element types, such as employing both solid elements and beam elements. In this section, 3D fatigue crack propagation analysis based on global-local numerical model is implemented and verified.

The analytic target herein is the plain welded steel beam tested by Fisher, as recorded in NHCRP report 102 (Fisher et al. 1970). The loading scheme was four-point bending. In terms of the global-local modelling, the pure bending segment was simulated by refined solid elements and other segments are simulated by shell elements. The adjacent segments were connected by 'Shell-to-Solid Coupling' interaction in ABAQUS (Hibbit et al. 2004), as shown in Fig. 1. The geometric profile of the beam was set exactly according to the original experimental report. The procedure of the 3D mixed mode fatigue crack propagation analysis approach can be referred to Zong et al. (2017b) and would not be illustrated in detail herein. The key issues that need to be clarified were the settings of 


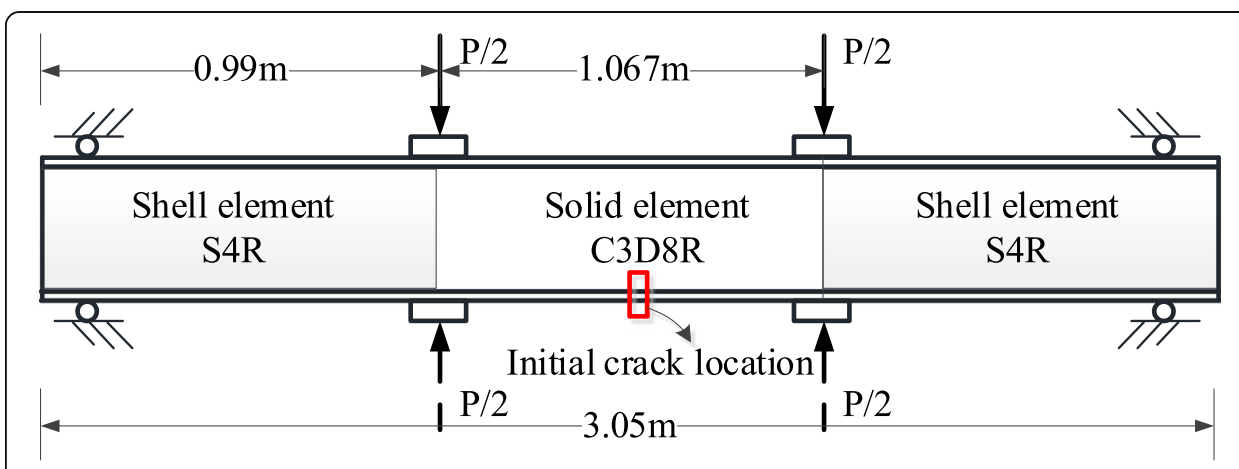

Fig. 1 The global-local prototype for steel welded beam

initial crack and critical crack. In terms of the initial crack, it was found by Fisher that the crack causing failure initiated in most cases at a flaw in the fillet weld at the flange-to-web junction. This kind of flaw was usually an inescapable gas pocket. Therefore, an initial circular crack was chosen, of which the circle center was settled at the flange-to-web junction of the mid-span section of the beam in the global-local model. The initial size of the circle crack was taken as $0.3 \mathrm{~mm}$ according to Ibsø and Agerskov (1996) and Zong et al. (2017b) (Fig. 2c). In terms of the critical crack, it was found that most cracks would penetrate the flange plate and develop along the web. The average penetration size in the web based on statistical analysis was about $40 \mathrm{~mm}$, and this criterion was employed for the determination of critical size (Fig. 2d).

Upon the settings of initial and critical fatigue crack, along with the fatigue crack growth rate parameters in accordance with Paris Law calibrated by Fisher et al. (1970) $(C=1.23 \times$ $10^{-13}, m=3$ in terms of ' $\mathrm{N}$ mm' unit system), the fatigue crack propagation analysis can be carried out utilizing Franc3D (2011) and ABAQUS. It should be noted that the analysis may encounter a technical problem, that was the adaptive meshing by Franc3D will fail when the intersection of the crack and the surface of the components occurred. Fortunately, the crack front at every analysis step can be recorded and then inserted into the FE model manually. For the fatigue assessment of the fillet welds at the flange-to-web junction, the intersection of the crack front and the surface of the components usually occurred two times, leading to three separate crack fronts finally, as shown in Fig. 3.

Considering the complete fatigue crack propagation process, the predicted fatigue lives based on the global-local FE model is shown in Fig. 4. Thanks to Fisher's

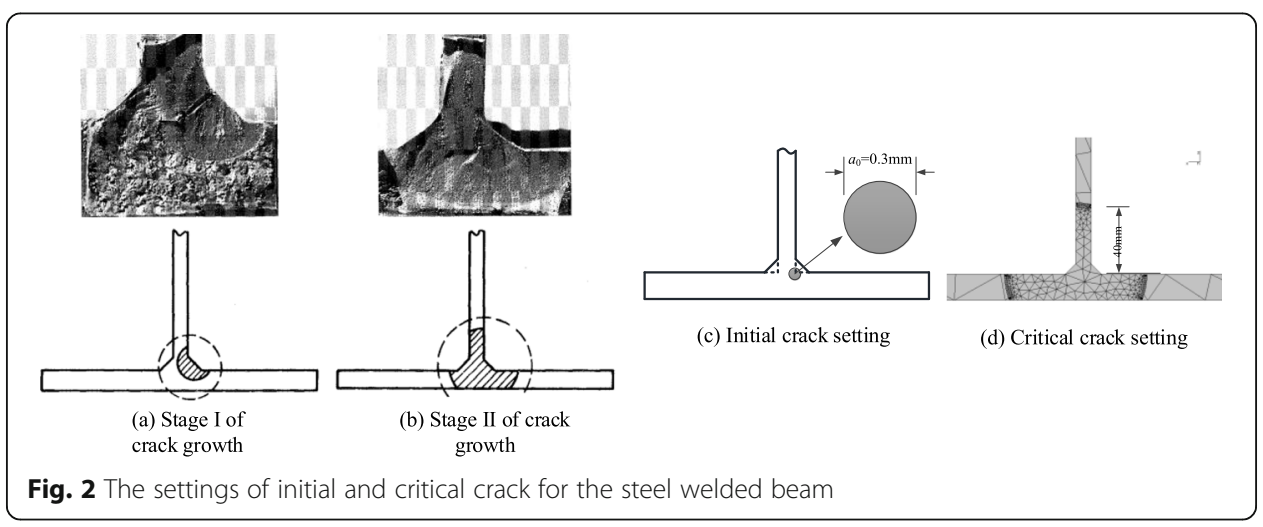




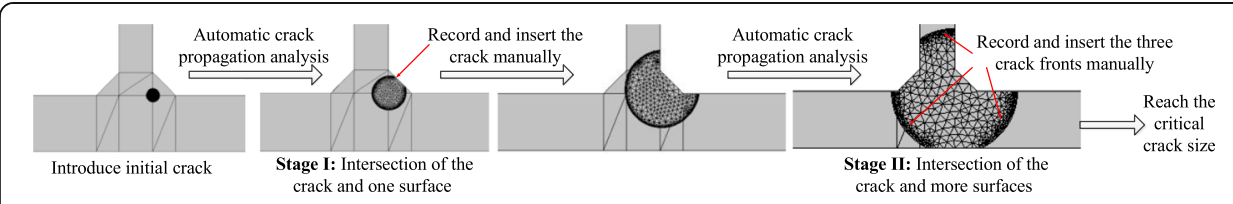

Fig. 3 The fatigue crack propagation analysis process for the steel welded beam

distinguished contribution, we have 55 effective fatigue life data for plain steel welded beams, which are adequate for the verification of the simulated results. It can be observed that a satisfying agreement is achieved between FE and experimental data, which proves the effectiveness and accuracy of the 3D fatigue crack propagation analysis based on the global-local model.

\section{Background case}

Owing to the verified 3D fatigue crack propagation analysis based on global-local model, it is promising to introduce this approach into the fatigue evaluation of practical engineering projects from the global structure level instead of component level. In this section, a typical steel truss bridge, Beijing LuGou Railway Bridge, was taken as a case project. The bridge was a two-way railway bridge, built in 1898. After 90 years, all the steel trusses were replaced by totally new prefabricated steel truss beams. Therefore, it can be regarded as a 'new' steel bridge and its life starts exactly from 1988, as shown in Fig. 5. The new bridge is composed of 15 span simply supported beams with $31.68 \mathrm{~m}$ span length. The steel grade is $16 \mathrm{Mnq}$ of which the yield strength is no less than 345 MPa. The design scheme of one representative span is shown in Fig. 6.

After the 'New' LuGou bridge was assembled in 1988, a systematic static load test on site for the bridge was conducted to examine the design rationality and construction quality (Beijing Railway Bureau 1988). The load was implemented by steam locomotives of Qianjin model, whose axle load distribution is shown in Fig. 7. There were two loading schemes in total, one was single-side loading with

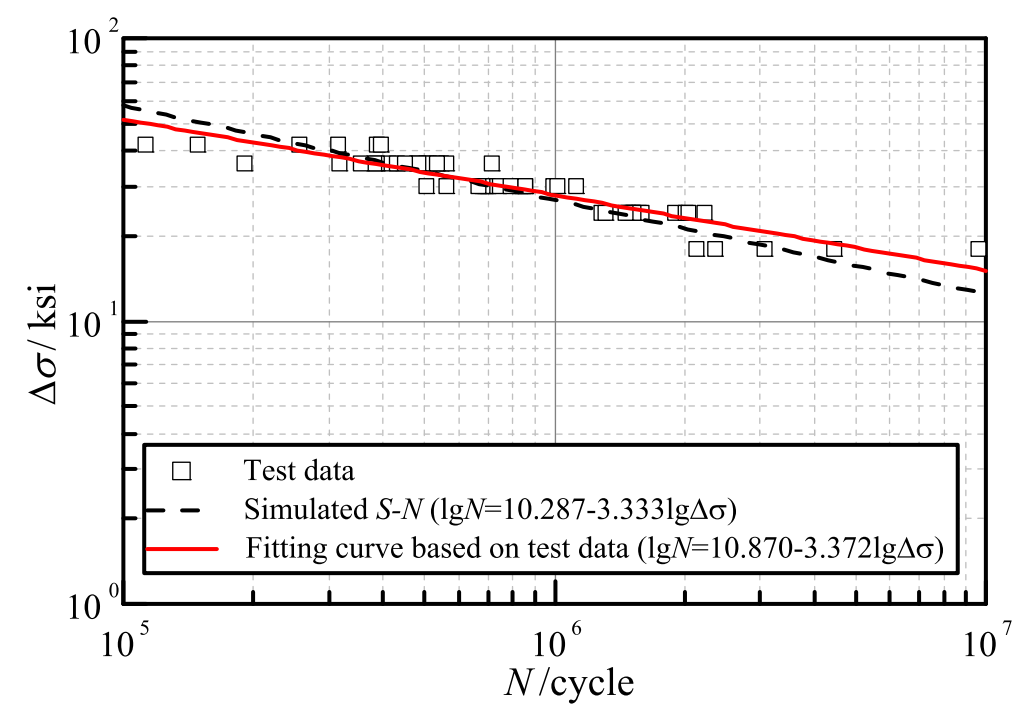

Fig. 4 Comparison between the test data and the predicted fatigue life 


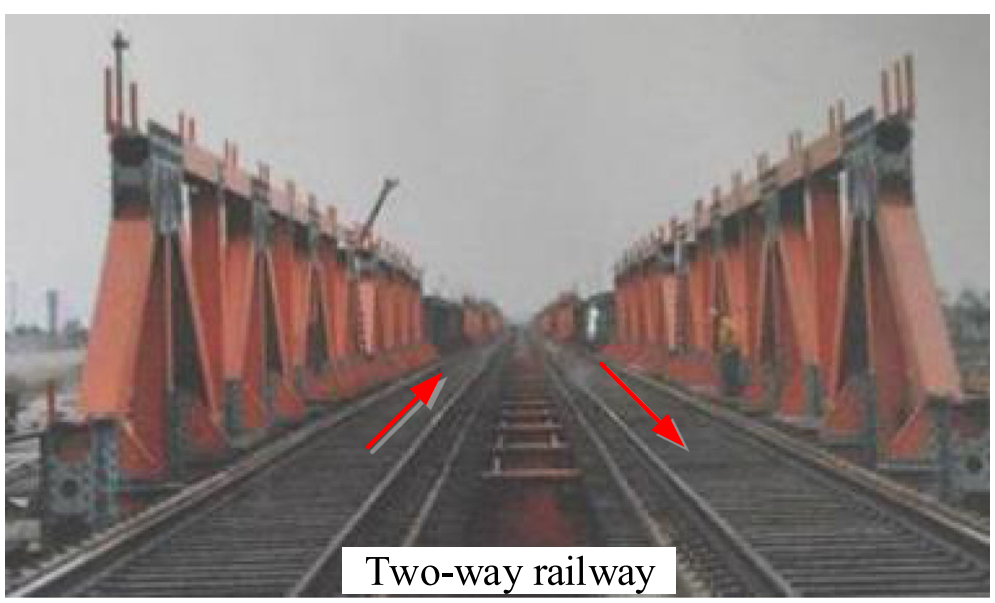

Fig. 5 'New' LuGou Railway Bridge in 1988

one locomotive, and the other one was double-sides loading with two locomotives. Each scheme was composed of six loading conditions according to the location of the axle, as illustrated in Table 1. The deflection and stress of typical members were carefully measured and recorded, which provided sufficient data for verifying the numerical model.

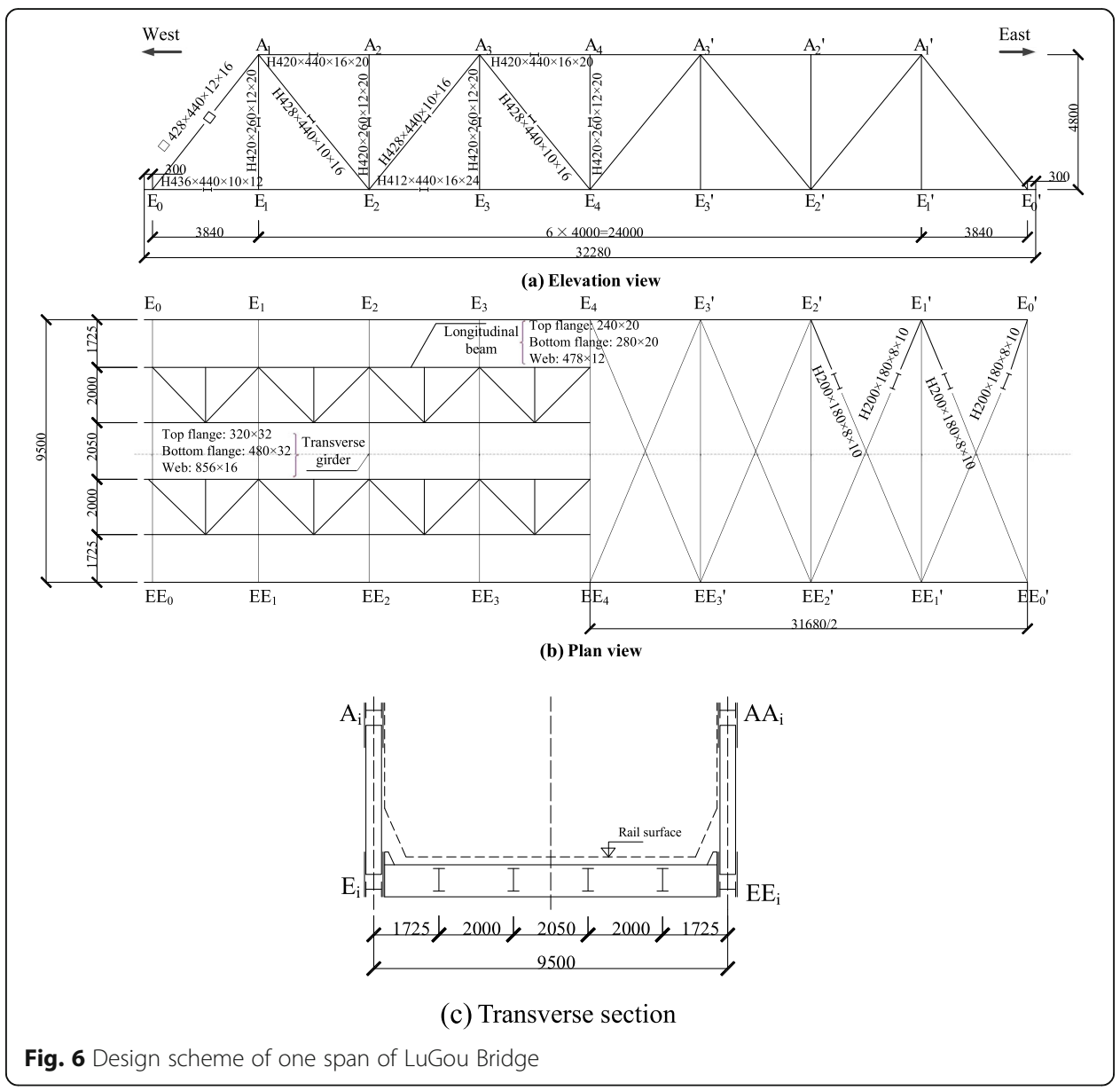




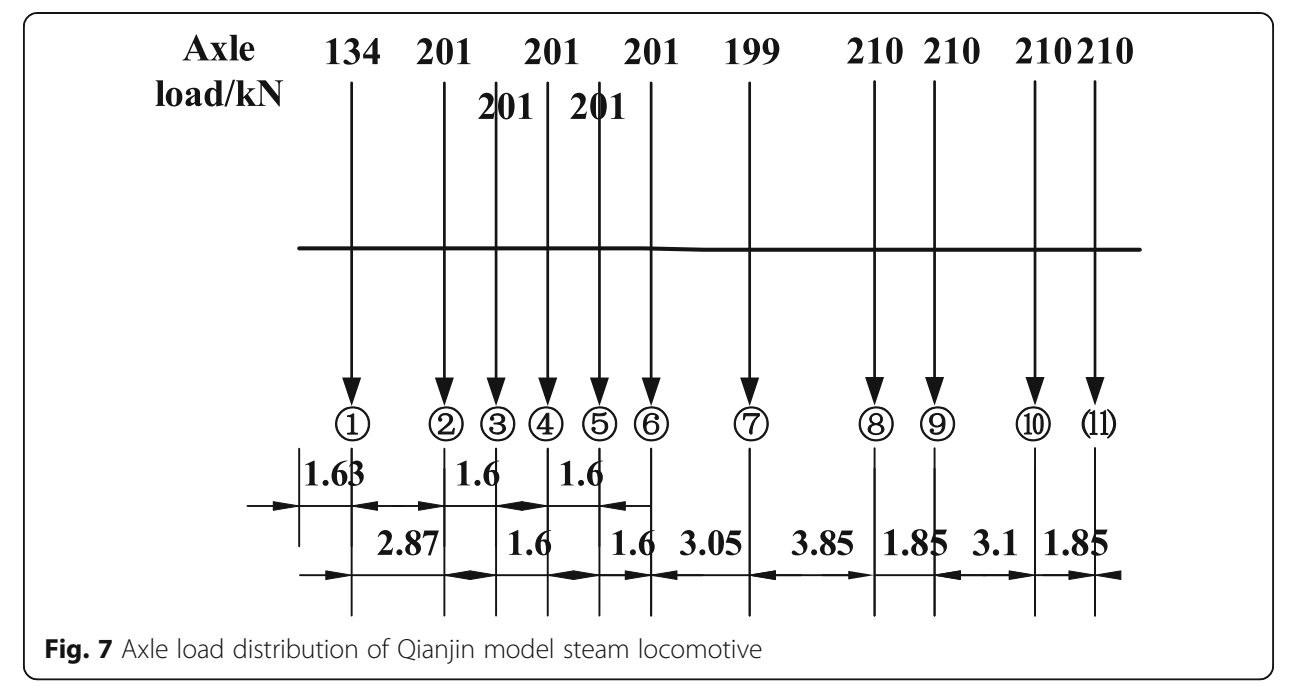

Based on the geometric profile illustrated in the construction drawings of the steel truss bridge, the FE model was established by ABAQUS, as shown in Fig. 8a. The vertical web members locating in the midspan of top chord segment were almost not subjected to stress and were simulated by beam element B31. Other parts of steel truss bridge were modelled by shell element S4. The preloaded high strength bolt connections of the bracings and the gusset plates were assumed rigid and realized by the TIE option, which was a surface-based constraint to make all Degree of freedoms (DOFs) equal for a pair of surfaces (Zhou et al. 2013). The wood sleeper was modelled by solid elements C3D8R and the rails were modelled by beam element B31. The rail pads that fasten the rails to the sleepers were simulated by springs \& dashpots between the beams and the mass points, with stiffness $K_{\mathrm{rp}}=500 \mathrm{MN} / \mathrm{m}$ and damping coefficient $C_{\mathrm{rp}}=200 \mathrm{kN} \cdot \mathrm{s} / \mathrm{m}$ (Zhou et al. 2013). The vertical bending stiffness of the rail is $6.4 \times 10^{6}$ $\mathrm{N} \cdot \mathrm{m}^{2}$ and the linear density is $60 \mathrm{~kg} / \mathrm{m}$ (Zhou et al. 2013). Simply supported boundary conditions were applied, where the longitudinal movement of one end was fixed and the other end was released. Thanks to the detailed site inspection data, the feasibility of the established FE model was verified through the comparison between the simulated and measured data, as presented in Fig. 9.

Meanwhile, a comprehensive survey on the loading history of LuGou Bridge was carried out by the authors. Generally, the loading history of the bridge can be divided into four stages. A typical type of passenger train and freight train were chosen for each stage (see Table 2). The distribution of the axle load of each train is shown in Appendix. Then the structural response of the bridge under the passage of the

Table 1 The loading scheme of static test for LuGou Bridge

\begin{tabular}{llll}
\hline Location No. & Loading Scheme $\mathbf{1}$ & Loading Scheme $\mathbf{2}$ & Location of the axle \\
\hline 1 & Single side & Double sides & Wheel (6) located at E4 axis \\
2 & Single side & Double sides & Wheel (5) located at E3 axis \\
3 & Single side & Double sides & Wheel (4) located at E3 axis \\
4 & Single side & Double sides & Wheel (2) located at E4 axis \\
5 & Single side & Double sides & Wheel (2) located at E1 axis \\
6 & Single side & Double sides & Wheel (10) located at E3 axis \\
\hline
\end{tabular}




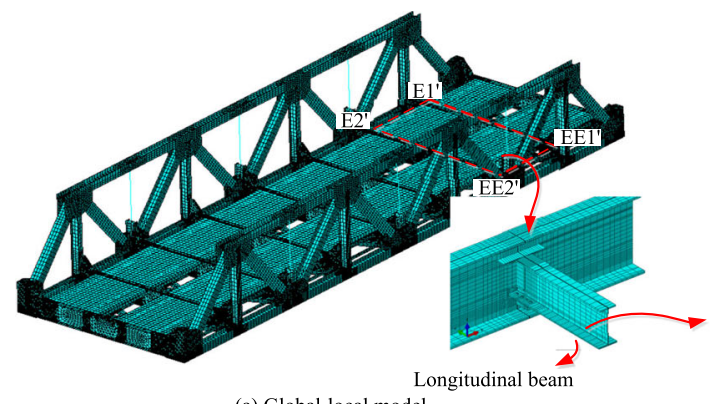

(a) Globat local model

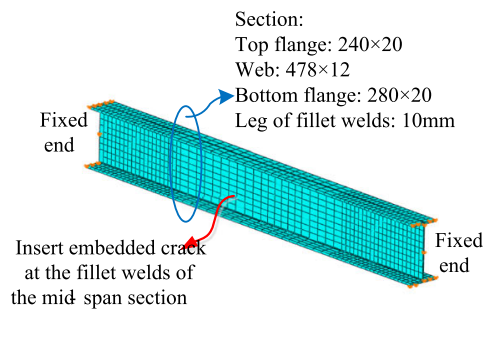

(b) Local model

Fig. 8 Global-local model and local model of the bridge

typical trains can be calculated and analyzed accordingly with the employment of the subroutine DLOAD (Hibbit et al. 2004).

For a steel truss bridge using friction type high strength bolted connections, its fatigue resistance is relatively good, while, the fatigue performance of some structural details should be paid attention, among which the longitudinal steel welded beam is a noteworthy fatigue prone component. The fatigue failure mode of the beam under bending moment was mainly located in the fillet welds of at the flange-to-web junction, as examined by Fisher et al. (1970). According to Eurocode 3, the design $S$ - $N$ curve specified for the fillet welds of steel welded beam is FAT112, which means the fatigue strength in terms of $2 \times 10^{6}$ cycles' life is $112 \mathrm{MPa}$. Then the fatigue damage under a typical train passage can be obtained based on Palmgren-Miner linear damage rule

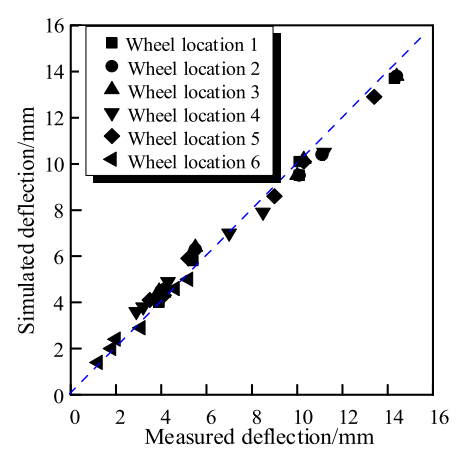

(a) Deflection of main truss under single side loading

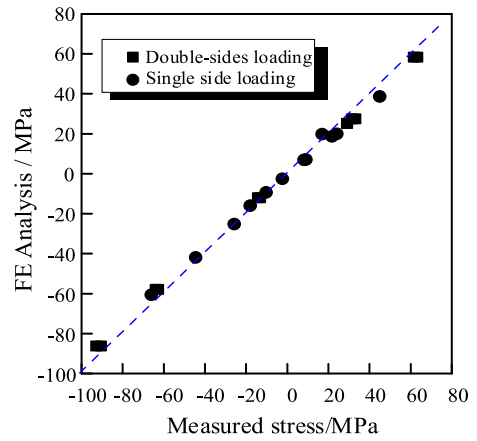

(c) Stress of main truss under single side loading

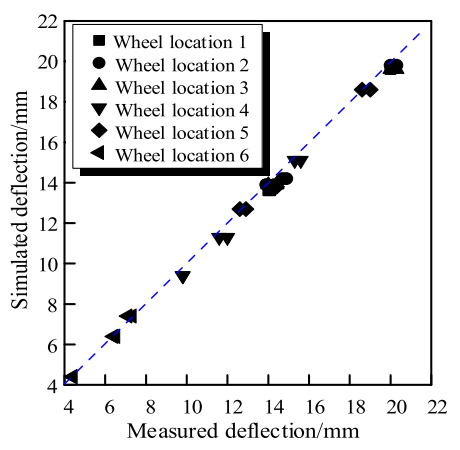

(b) Deflection of main truss under double sides loading

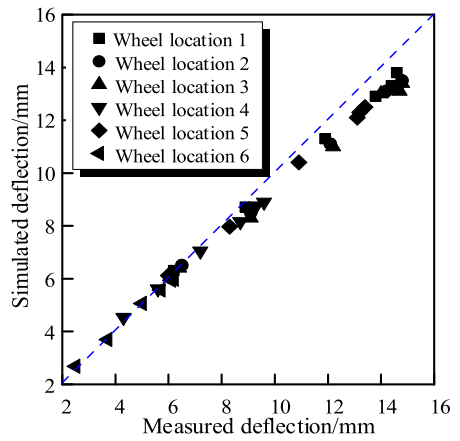

(d) Deflection of girder under single side loading

Fig. 9 Comparison between the measured and simulated results in terms of the static inspection 
Table 2 Loading history survey of LuGou Bridge

\begin{tabular}{|c|c|c|}
\hline Stage & Typical Passenger Train & Typical Freight Train \\
\hline \multicolumn{3}{|l|}{ Stage 1: 1988 1997 } \\
\hline Transportation volume & 20 pairs / day & 30 pairs / day \\
\hline Locomotive & Beijing Model (Diesel) & Jianshe Model (Steam) \\
\hline Carriage marshalling & 14 uniform carriages & 50 open wagons ( $\mathrm{C} 50$ ) and 10 box wagons (P65) \\
\hline Train speed & $50 \sim 60 \mathrm{~km} / \mathrm{h}$ & $20 \sim 30 \mathrm{~km} / \mathrm{h}$ \\
\hline Abbreviation label & BJKC & JSHC \\
\hline \multicolumn{3}{|l|}{ Stage 2: 1997 2007 } \\
\hline Transportation volume & 5 pairs / day & 50 pairs / day \\
\hline Locomotive & Dongfeng Four model & Dongfeng Four model \\
\hline Carriage marshalling & 14 uniform carriages & 50 open wagons (C60) and 10 box wagons (P65) \\
\hline Train speed & $60 \sim 70 \mathrm{~km} / \mathrm{h}$ & $50 \sim 60 \mathrm{~km} / \mathrm{h}$ \\
\hline Abbreviation label & DFKC & DFHC \\
\hline \multicolumn{3}{|l|}{ Stage 3: 2007 2012 } \\
\hline Transportation volume & 3 pairs / day & 50 pairs / day \\
\hline Locomotive & Shaoshan Four model & Shaoshan Four model \\
\hline Carriage marshalling & 14 uniform carriages & 50 open wagons (C62) and 10 box wagons (P65) \\
\hline Train speed & $60 \sim 70 \mathrm{~km} / \mathrm{h}$ & $50 \sim 60 \mathrm{~km} / \mathrm{h}$ \\
\hline Abbreviation label & SSKC & SSHC \\
\hline \multicolumn{3}{|l|}{ Stage 4: 2012 till now } \\
\hline Transportation volume & 11 pairs / day & 20 pairs / day \\
\hline Locomotive & Harmony model & Harmony model \\
\hline Carriage marshalling & 16 uniform carriages & 50 open wagons (C64) and 10 box wagons (P65) \\
\hline Train speed & Less than $100 \mathrm{~km} / \mathrm{h}$ & Less than $60 \mathrm{~km} / \mathrm{h}$ \\
\hline Abbreviation label & HXKC & $\mathrm{HXHC}$ \\
\hline
\end{tabular}

(Fig. 10a and b) (Palmgren 1924; Miner 1945). Accordingly, the cumulative fatigue damage until year 2015 can be calculated (Fig. 10c). It was observed that the maximum fatigue damage occurs at the west of the axis line E1'EE1' and the damage was up to the order of $10^{-2}$. What's more, LuGou Bridge would be mainly used for freight trains in the future and its residual life under possible heavy axle loads should be carefully examined. In this study, we would refine the modelling of the longitudinal beam between the axis line E1'EE1' and E2'EE2' with solid elements (Fig. 8a) and conduct its fatigue life prediction in the whole structural model. Meanwhile, a refined local model of the longitudinal beam (Fig. 8b) with fixed end boundary conditions was established for contrastive study, to investigate the effect of global-local interaction on the fatigue life of structural details.

\section{Fatigue crack propagation analysis}

\subsection{Equivalent constant stress range}

The 3D fatigue crack propagation analysis was difficult to be implemented under moving load input due to the caused variable stress range. Therefore, the first step of the analysis was to transfer the variable stress range under moving load into an equivalent 


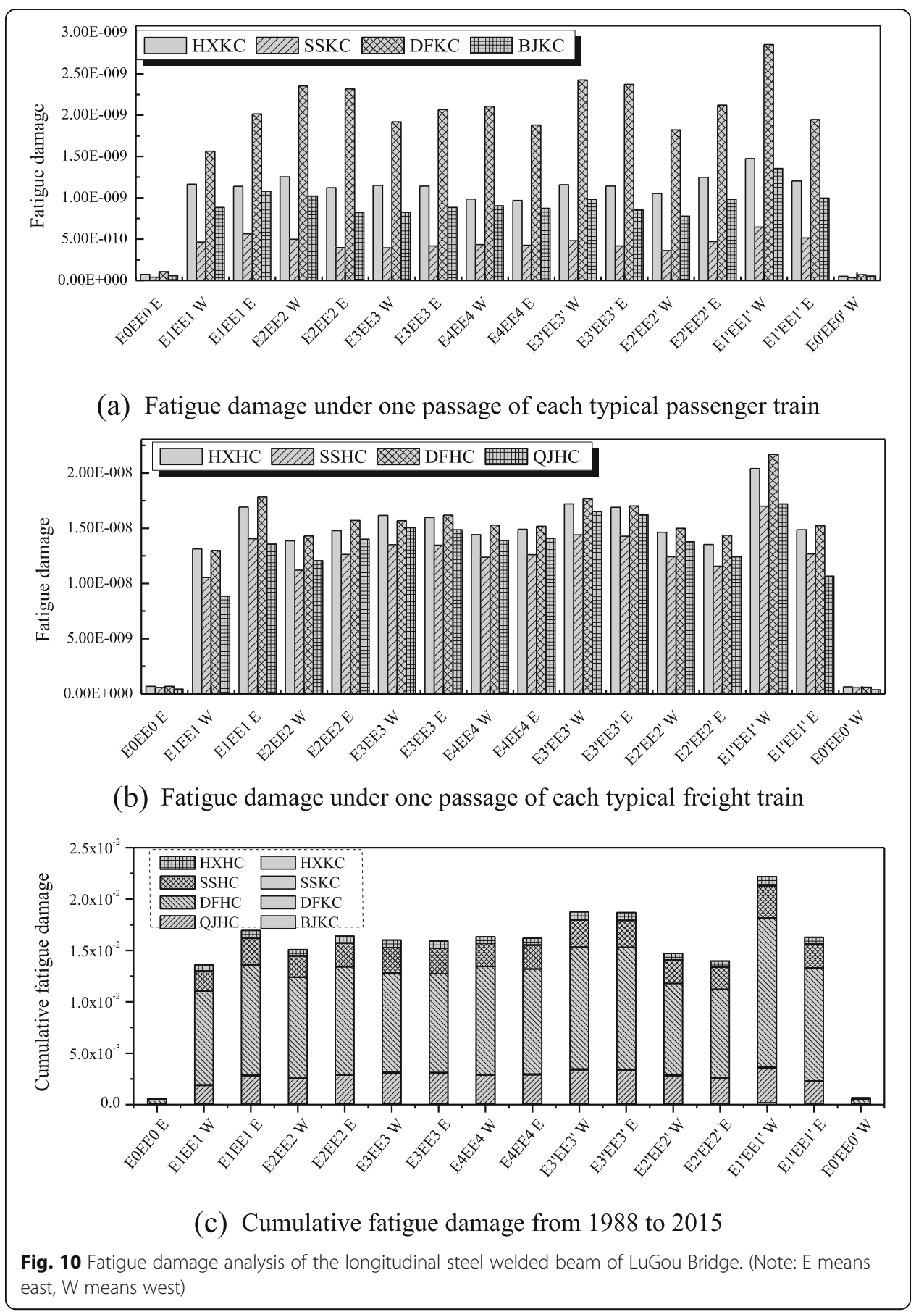

constant stress range. In this study, the equivalent crack extension principle was utilized. Following this principle, the variable amplitude stress history generated by a single train passage was treated as a typical stress block and the equivalent stress range $\Delta \sigma_{\text {eq }}$ was calculated based on the assumption of that, an equivalent crack extension was produced by a single stress cycle of $\Delta \sigma_{\text {eq }}$ and by several stress cycles due to one train passage. The detailed description of the calculation procedure was given by Zhou et al. (2016). The formulation of $\Delta \sigma_{\text {eq }}$ can be written as 


$$
\Delta \sigma_{\mathrm{eq}}=\left[\frac{\Delta a}{C(Y \sqrt{\pi \bar{a}})^{m}}\right]^{1 / \mathrm{m}}
$$

where, $\Delta a$ is the total crack extension size during one train passage; $\bar{a}$ is the average crack size estimated as $\bar{a}=a_{0}+\Delta a / 2 ; C$ and $m$ are the constant parameters in Paris Law; $Y$ is the geometric correction factor. Upon the assumption of the initial circular crack for the fillet welds at the flange-to-web junction, the crack at the tensile flange side can be regarded as an embedded circular flaw in a finite width plate subjected to tension, as shown in Fig. 11. The solution of $Y$ can be referred to BS7910 (BSI 2005b).

Then the equivalent stress range $\Delta \sigma_{\text {eq }}$ in terms of a passage of each typical train can be calculated, as shown in Table 3. For the refined local model, it is very easy to realize the computed $\Delta \sigma_{\text {eq }}$ input by applying a concentrated force at the mid-span of the beam. For the global-local model, the axle load of the typical train needs to be magnified for the input of $\Delta \sigma_{\mathrm{eq}}$. However, the amplifying load will enlarge the stress of the other parts of the global structure, which may lead to incorrect boundary conditions for the longitudinal beam. Therefore, another equivalent principle is employed, that is the fatigue damage under a passage of a typical train equals to the damage under $n_{\text {eq }}$ times of loading-unloading of the train at the most unfavorable axle distribution location for the concerned details.

Accordingly, $n_{\mathrm{eq}}$ is given by

$$
n_{\mathrm{eq}}=\left[\frac{\Delta \sigma_{\mathrm{eq}}}{\Delta \sigma_{\mathrm{max}, \mathrm{s}}}\right]^{\beta_{s}}
$$

where, $\Delta \sigma_{\max , \mathrm{s}}$ is the stress range caused by the loading-unloading of the train at the most unfavorable axle distribution location for the concerned details; $\beta_{\mathrm{s}}$ is the power exponent of the relevant $\mathrm{S}-\mathrm{N}$ curve and is taken as 3.0 herein. Take the typical train $\mathrm{HXHC}$ as an example, the corresponding $\Delta \sigma_{\mathrm{eq}}$ is $46.69 \mathrm{MPa}$ and $\Delta \sigma_{\mathrm{max}, \mathrm{s}}$ is $25.75 \mathrm{MPa}$, then we can conclude that a passage of $\mathrm{HXHC}$ is equivalent to 5.96 times of loadingunloading of $\mathrm{HXHC}$ at the most unfavorable axle distribution location.

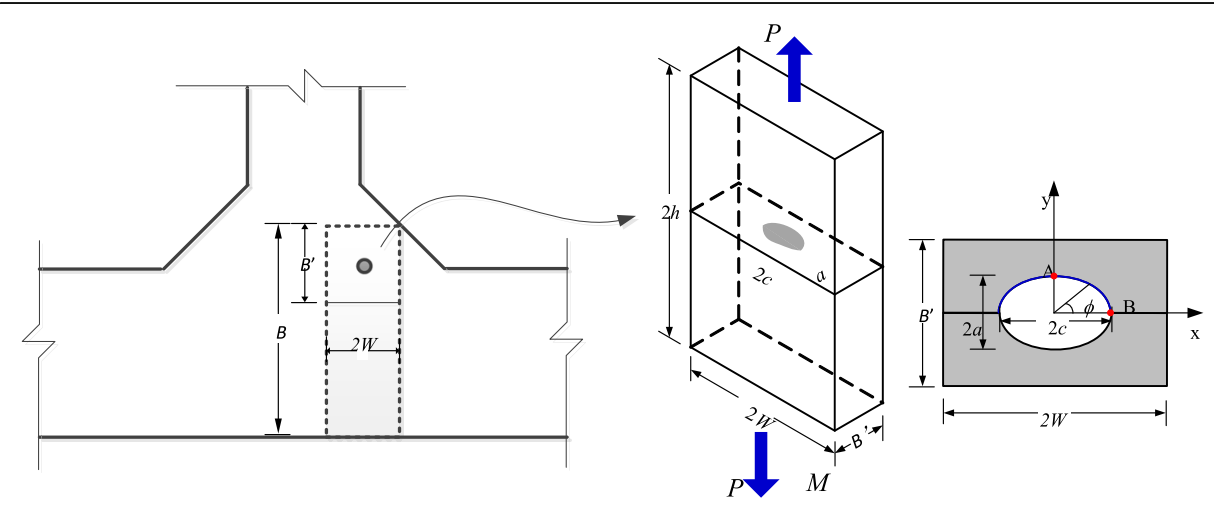

Fig. 11 Geometric model for the assumption of embedded flaw under tension 
Table 3 Equivalent stress range of one passage of each typical train

\begin{tabular}{lllllllll}
\hline Typical train type & BJKC & QJHC & DFKC & DFHC & SSKC & SSHC & HXKC & HXHC \\
\hline$\Delta \sigma_{\text {eq }} / \mathrm{MPa}$ & 27.14 & 45.12 & 31.51 & 47.26 & 23.41 & 45.01 & 27.61 & 46.69 \\
\hline
\end{tabular}

\subsection{Comparison between the results obtained from the local and global-local model}

Thanks to the equivalent stress range obtained in last section, the 3D fatigue crack propagation analysis based on local model and global-local model can be carried out respectively. The initial crack setting is exactly same with section 2 , while, slight change is made for the determination of the critical crack. Considering the design conservatism, the critical crack is chosen as the size when the crack is about to fully penetrate the flange plate, as shown in Fig. 12a. The fatigue crack growth parameters in terms of Paris Law are determined according to Zong et al. (2015), that is, $C$ and $\mathrm{m}$ are taken as 7.16e-12 and 2.57, respectively. Afterwards, the relationship between the stress intensity factor range $\Delta K$ and the crack size $a$ can be simulated. The $a-\Delta K$ data along the vertical crack growth route as shown in Fig. 12a was employed for calculating the fatigue crack propagation life. It can be observed that the $a-\Delta K$ relationship under HXHC train based on global-local model and local model is almost same (Fig. 12b), if the $\Delta K$ based on local model multiplies a reduction factor which is exactly the ratio of the stress range in global-local model over that in local model (e.g. the factor is 25.75/46.69=0.55 for $\mathrm{HXHC}$ train). It is illustrated that there is no difference in terms of the fatigue crack growth mechanism between the simulation between global-local model and local model. This is mainly because that the stress level of the whole bridge structure is relatively low, and the interaction between the local damage evolution and the global structural response is not obvious. It is hopefully to conclude with the suggestion that the refined local model is accurate enough for fatigue assessment of a specific structural detail, if the detail locates in an overall 'elastic' status.

Based on the simulated $a-\Delta K$ relationship, the fatigue crack propagation life can be obtained through Runge-Kutta integration. Figure 13a provided a typical relationship between crack size and life represented by the number of train passages. The figure was established under the assumption that there was only one typical train, HXHC on the target steel bridge. It can be observed, as illustrated before, the life prediction results based on global-local model and local model completely matched. Afterwards,

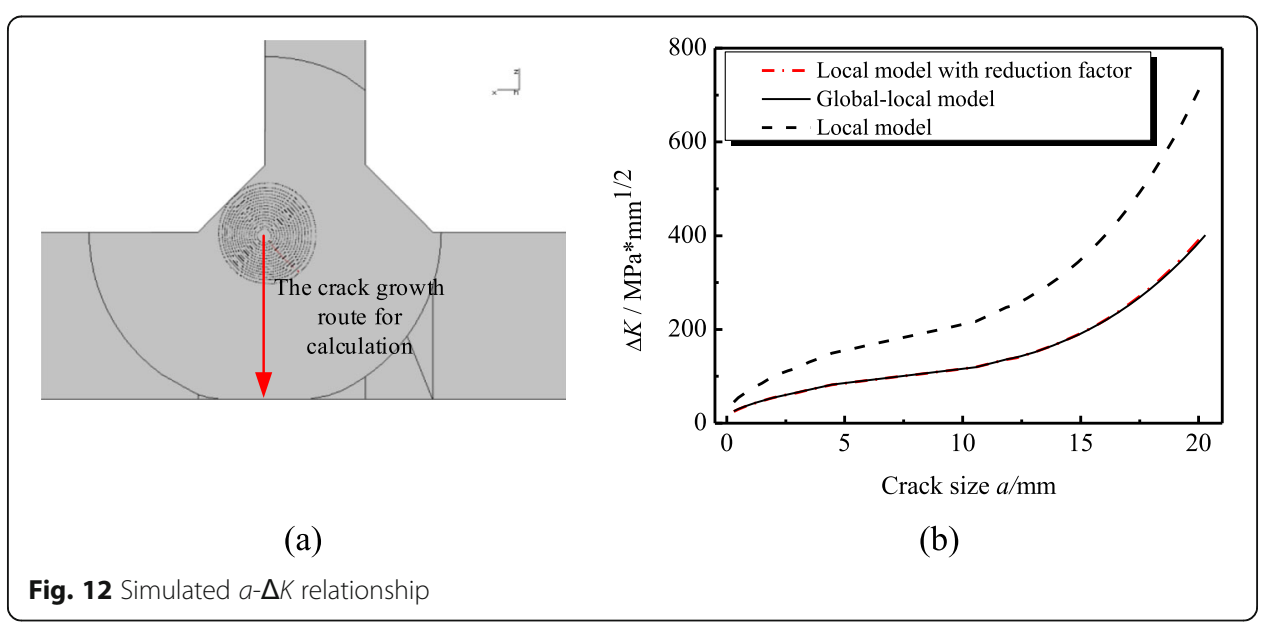




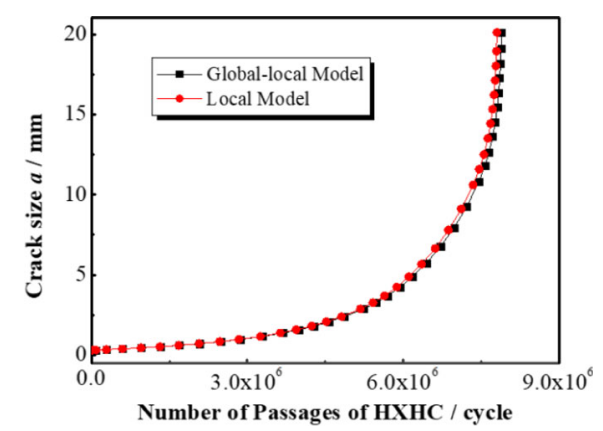

(a) Residual life assuming only HXHC passes the bridge

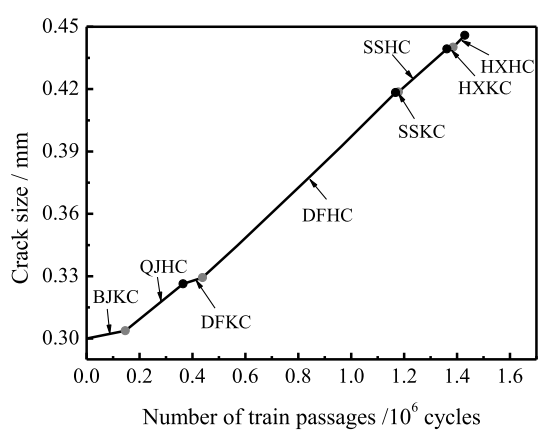

(b) Fatigue crack growth process from 1988 to 2015

Fig. 13 Representative calculation results based on 3D propagation analysis

the fatigue crack propagation process of the longitudinal steel welded beam in the bridge under the real loading history was reproduced. It should be noted that the passenger trains and freight trains were under service concurrently during each stage of the bridge's loading history, while, it was assumed herein, for the sake of simplicity, that the passenger trains passed the bridge firstly and then the freight trains came. As a result, it can be found that the size of the embedded crack in the fillet welds of the longitudinal steel welded beam of the bridge only has a $0.145 \mathrm{~mm}$ growth from 1988 to 2015. Assume the bridge will be used for the freight transportation and only HXHC will pass through the bridge in the future, the residual life is $6.44 \times 10^{6}$ cycles of train passages.

\subsection{Residual life prediction under future heavy loading wheels}

With the rapid development of high-speed railways and the enhancement of the passenger capacity, more and more existing railways are released for freight transportation, as mentioned before. It has been presented the residual life of the bridge under the condition that only HXHC train keep passing the bridge in the future. However, the fact is probably more challenging due to the operation of more heavy loading wheels, as the heavy haulage is one of the most effective approaches to improve the transport efficiency and economic benefit. According to the survey of relevant authorities, two types of freight train will probably be employed in the future, with the axle load as large as to 27 tons and 30 tons respectively. The axle load distribution of the two heavy haul trains are shown in Fig. 14.

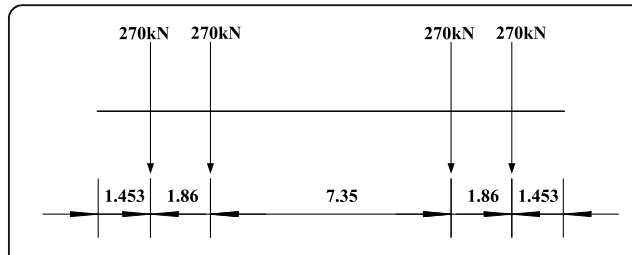

(a) Axle load $=27$ tons

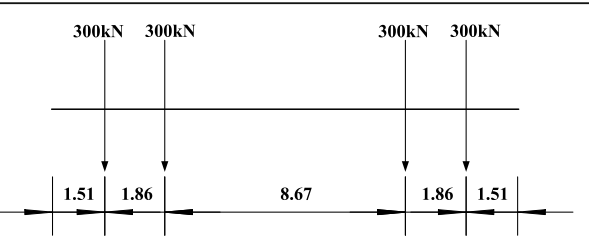

(b) Axle load $=30$ tons

Fig. 14 Axle load distribution of heavy haul train 


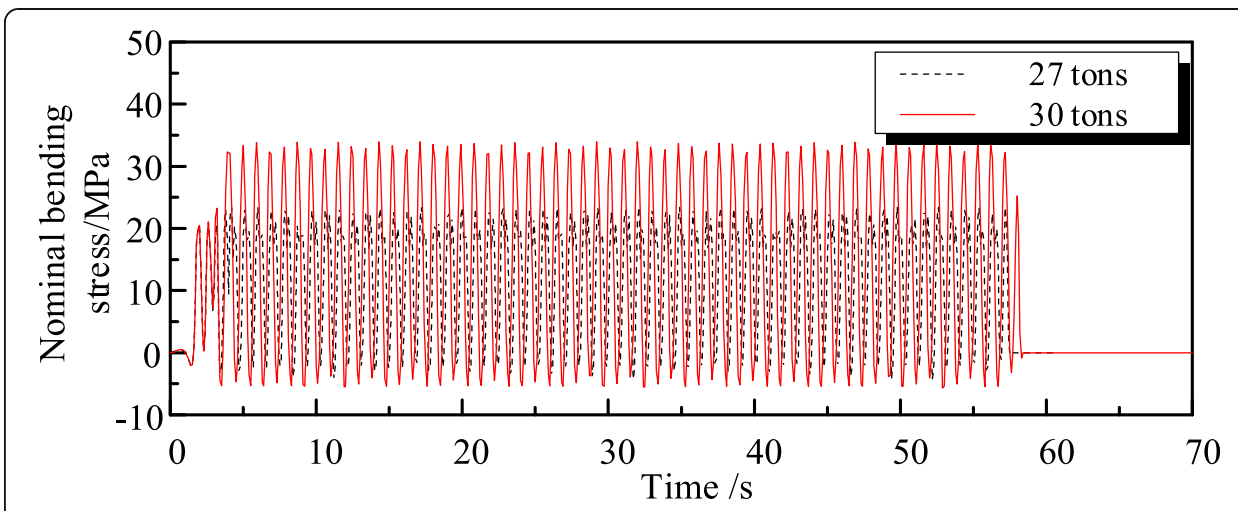

Fig. 15 Stress response history under the passage of heavy haul trains

Thanks to the previous analysis, it could be stated that the LuGou bridge has an excellent fatigue resistant performance. However, the fatigue performance should be reassessed if the bridge will bear heavy loading wheels. Based on the current arrangement of HXHC, keep the haulage motor as the Harmony model, and replace all the traction carriages by the two types of trains. Then a marshalling of freight trains with heavy loading wheels is completed, which is utilized for the fatigue assessment of the bridge.

Figure 15 presents the stress response history of the target structural detail in the bridge under one passage of 27 tons and 30 tons heavy haul train respectively. Then the equivalent stress range is calculated accordingly, as shown in Table 4, and the fatigue crack growth along with the increasing passages of the trains is simulated, as presented in Fig. 16. It can be clearly found that the residual fatigue life of the target detail has a significant reduction along with the increasing of the axle load. The residual life is only 48 years keeping bearing the passage of the 30 tons train. Therefore, it can be concluded that the increasing of the axle load is totally challenging and it requires a comprehensive, detailed and cautious technical examination and operation plan.

\section{Conclusions}

In this study, three-dimensional (3D) fatigue crack propagation analysis approach based on global-local numerical model was implemented, examined and then introduced into a typical steel truss bridge for realizing more refined fatigue assessment from the global structural level. Key conclusions and suggestions according to the research work in this study can be drawn:

(1) With the help of the abundant experimental data obtained by Fisher et al. (1970), it was verified that the global-local FE model based fatigue crack propagation

Table 4 Equivalent stress range of each heavy haul train and corresponding residual life

\begin{tabular}{llll}
\hline & $\begin{array}{l}\Delta \boldsymbol{\sigma}_{\text {eq }} \text { I } \\
\mathbf{M P a}\end{array}$ & $\begin{array}{l}\text { Fatigue life in terms of the number of train passages } \\
\text { /cycle }\end{array}$ & $\begin{array}{l}\text { Fatigue life in terms of time / } \\
\text { years }\end{array}$ \\
\hline $\mathrm{HXHC}$ & 46.69 & $6.85 \times 10^{6}$ & 235 \\
27 & 58.73 & $3.78 \times 10^{6}$ & 129 \\
tons & & & 48 \\
30 & 86.23 & $1.41 \times 10^{6}$ & \\
tons & & & \\
\hline
\end{tabular}




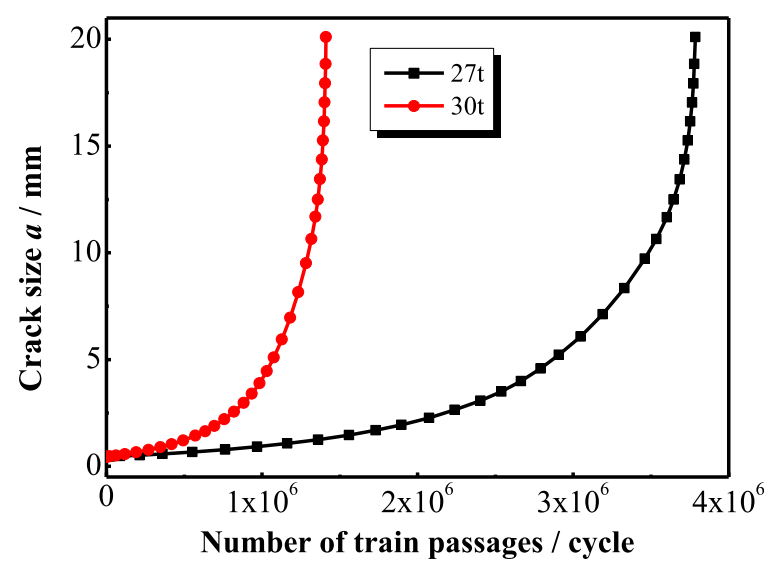

Fig. 16 The fatigue crack growth process under heavy axle load

analysis can provide an effective and accurate prediction on the fatigue propagation lives. This makes it feasible to conduct the fatigue evaluation from the structural level instead of the component level.

(2) The fatigue performance of the longitudinal steel welded beam in a steel truss bridge was investigated based on global-local model and local model respectively. It was found that there is no difference in terms of the fatigue crack growth mechanism between the simulation between global-local model and local model. It is hopefully to conclude with the suggestion that the refined local model is accurate enough for fatigue assessment of a specific structural detail, if the detail locates in an overall 'elastic' status.

(3) The effect of heavy haul train operation on the fatigue performance of the steel truss bridge was analyzed. It was observed that the residual life of the longitudinal steel welded beam would have an obvious reduction when the axle load was increasing. It is recommended that a comprehensive, detailed and cautious technical examination and regular recondition plan should be made when the heavier axle load is employed.

(4) The global-local interaction in terms of the fatigue assessment of the structure is still an issue that should be paid enough attention. This study only introduces the fatigue damage in one specific location and the stress level of the whole structure is relatively low. However, the global-local interaction effect should be further investigated when the stress level of the structure increases and multiple fatigue damage occurs in various structural details of the structure.

\section{Appendix}

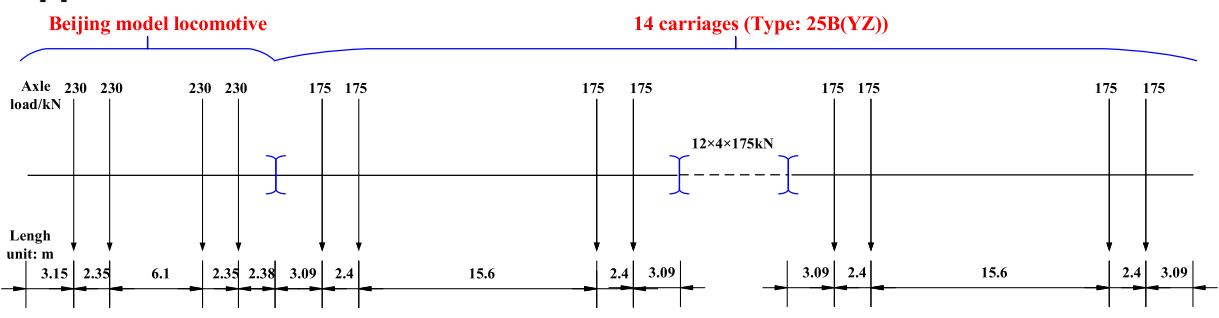

(a) Passenger train in Stage 1: BJKC 


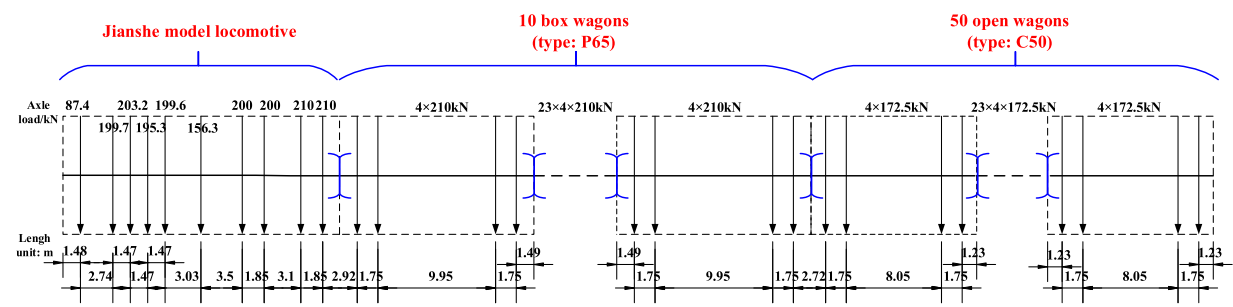

(b) Freight train in Stage 1: JSHC

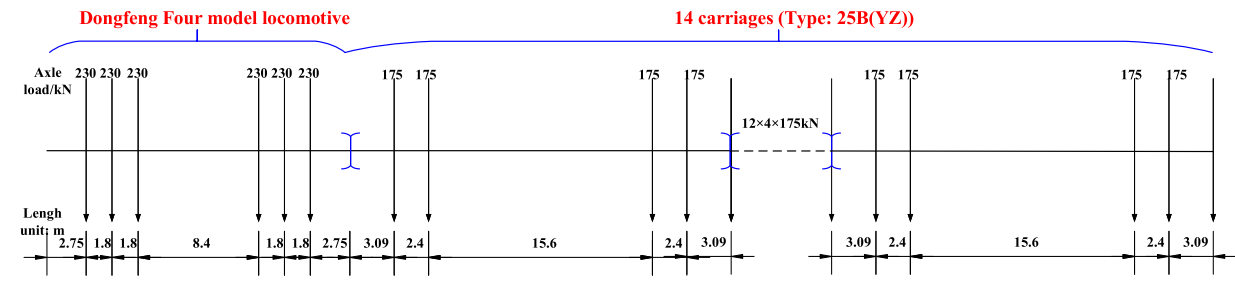

(c) Passenger train in Stage 2: DFKC

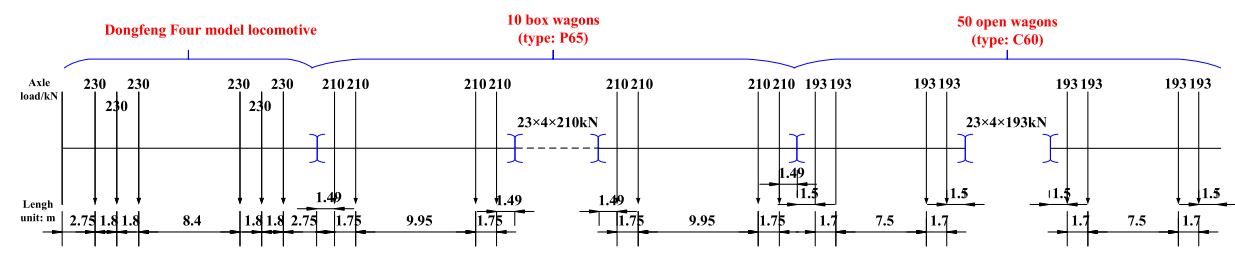

(d) Freight train in Stage 2: DFHC

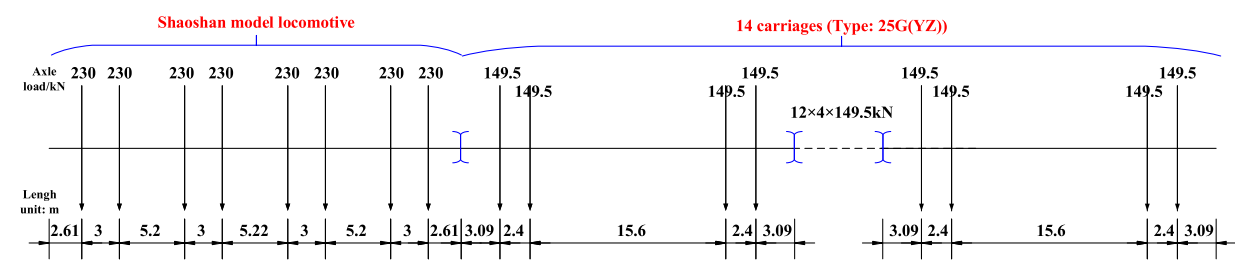

(e) Passenger train in Stage 3: SSKC

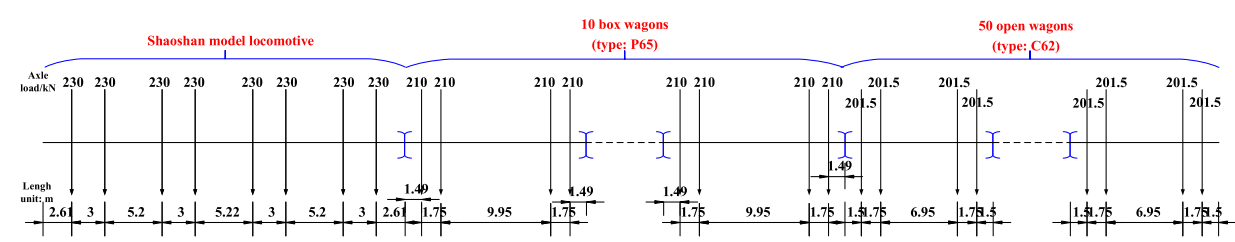

(f) Freight train in Stage 3: SSHC

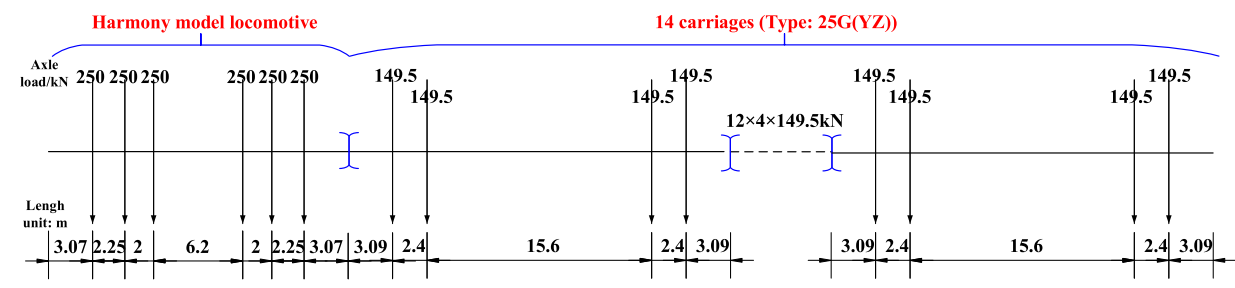


(g) Passenger train in Stage 4: HXKC

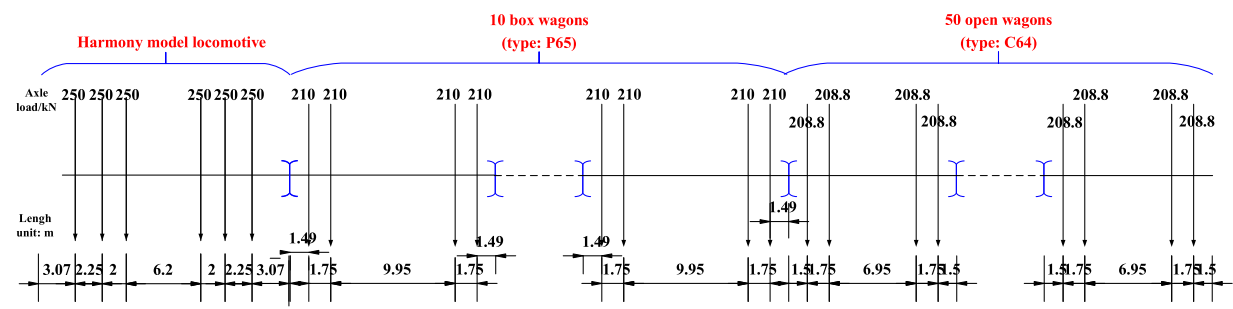

\section{(h) Freight train in Stage 4: HXHC}

\section{Abbreviations}

FE: Finite element; DOF: Degree of freedom; AASHTO: American Association of State Highway and Transportation Officials; FAT $x$ : Fatigue strength in terms of $2 \times 10^{6}$ cycles' life is $x \mathrm{MPa}$

\section{Acknowledgements}

The kind support on the permission to use Franc3D from Mr. Li Mengguang in MVT GROUP INC. is greatly appreciated.

\section{Authors' contributions}

Liang Zong: Conceptualization, Methodology, Analysis, Writing - Original Draft. Gang Shi: Supervision,

Conceptualization, Methodology. The author(s) read and approved the final manuscript.

\section{Funding}

The writers gratefully acknowledge the support for this work, which was sponsored by the National Natural Science

Foundation of China (No.51608359) and the open fund of State Key Laboratory of Subtropical Building Science (2018ZB24).

\section{Availability of data and materials}

The datasets used and analyzed during the current study are available from the corresponding author on reasonable request.

\section{Competing interests}

The authors declare that they have no competing interests.

\section{Author details}

${ }^{1}$ School of Civil Engineering, Tianjin University/ Key Laboratory of Coast Civil Engineering Structures Safety (Tianjin University), Ministry of Education, Tianjin 300072, China. ${ }^{2}$ Key Laboratory of Civil Engineering Safety and Durability of China Education Ministry, Department of Civil Engineering, Tsinghua University, Beijing 100084, China.

Received: 28 November 2020 Accepted: 21 December 2020

Published online: 06 January 2021

\section{References}

American Association of State Highway and Transportation Officials (1995) LRFD bridge design specifications, 3rd edn. AASH TO, Washington, DC

Barsoum Z (2008) Residual stress analysis and fatigue assessment of welded steel structures. Ph.D. dissertation. Royal Institute of Technology (KTH), Stockholm

Beijing Railway Bureau (BJRB) (1988) Static test report on LuGou steel bridge, Beijing

British Standards Institution (2005a) Eurocode 3: design of steel structures. British Standards Institution, London

British Standards Institution (2005b) BS 7910. Guide to methods for assessing the acceptability of flaws in metallic structures, British Standards Institution, London

Comeau MP, Kulak GL (1979) Fatigue strength of welded steel elements. Structural engineering report 79. University of Alberta, Canada

Fisher JW, Albrecht P, Yen BT, Klingerman DJ, McNamee BM (1974) Fatigue strength of steel beams with welded stiffeners and attachments. NCHRP report 147. Transportation Research Board, National Research Council, Washington, DC

Fisher JW, Frank KH, Hirt MA, McNamee BM (1970) Effect of weldments on the fatigue strength of steel beams, NCHRP report 102. Transportation Research Board, National Research Council, Washington, DC

Franc3D (2011) Reference manual for version 6. Fracture Analysis Consultants Inc. Retrieved from http://www.franc3d.com/. Hibbit D, Karlsson B, Sorenson P (2004) ABAQUS analysis user's manual, version 6.5. Hibbit, Karlsson \& Sorenson Inc., USA

Hobbacher AF (2009) The new IIW recommendations for fatigue assessment of welded joints and components - a comprehensive code recently updated. Int J Fatigue 31(1):50-58

Ibsø JB, Agerskov H (1996) An analytical model for fatique life prediction based on fracture mechanics and crack closure. J Constr Steel Res 37(3):229-261

Miner MA (1945) Cumulative fatigue damage. J Appl Mech 12(3):A159-A164

Palmgren A (1924) Die lebensdauer von kugellagern. Zeitschrift des Vereinesdeutscher Ingenierure 68(14):339-341 Wilson WM (1948) Flexural fatigue strength of steel beams; a report of an investigation conducted by the Engineering Experiment Station, University of Illinois 
Zhou H, Liu K, Shi G, Wang YQ, Shi YJ, DeRoeck G (2013) Fatigue assessment of a composite railway bridge for high speed trains. Part I: modeling and fatigue critical details. J Constr Steel Res 82:234-245

Zhou H, Shi G, Wang Y, Chen H, DeRoeck G (2016) Fatigue evaluation of a composite railway bridge based on fracture mechanics through global-local dynamic analysis. J Constr Steel Res 122:1-13

Zong L, Shi G, Wang Y (2015) Experimental investigation on fatigue crack behavior of bridge steel Q345qD base metal and butt weld. Mater Des (1980-2015) 66:196-208

Zong L, Shi G, Wang YQ, Li ZX, Ding Y (2017c) Experimental and numerical investigation on fatigue performance of nonload-carrying fillet welded joints. J Constr Steel Res 130:193-201

Zong L, Shi G, Wang YQ, Yan JB, Ding Y (2017b) Investigation on fatigue behaviour of load-carrying fillet welded joints based on mix-mode crack propagation analysis. Arch Civ Mech Eng 17(3):677-686

Zong L, Shi G, Wang YQ, Zhou H (2017a) Fatigue assessment on butt welded splices in plates of different thicknesses. J Constr Steel Res 129:93-100

\section{Publisher's Note}

Springer Nature remains neutral with regard to jurisdictional claims in published maps and institutional affiliations.

Submit your manuscript to a SpringerOpen ${ }^{\odot}$ journal and benefit from:

- Convenient online submission

- Rigorous peer review

- Open access: articles freely available online

High visibility within the field

- Retaining the copyright to your article

Submit your next manuscript at $\boldsymbol{\nabla}$ springeropen.com 